\title{
Racial/Ethnic Differences in Associations Between Neighborhood Social Cohesion and Meeting Physical Activity Guidelines, United States, 2013-2014
}

\author{
Stella S. Yi, $\mathrm{PhD} \mathrm{MPH}^{1}$; Chau Trinh-Shevrin, $\mathrm{DrPH}^{1}$; Irene H. Yen, $\mathrm{PhD}^{2}$; \\ Simona C. Kwon, DrPH ${ }^{1}$
}

Suggested citation for this article: Yi SS, Trinh-Shevrin C, Yen IH, Kwon SC. Racial/Ethnic Differences in Associations Between Neighborhood Social Cohesion and Meeting Physical Activity Guidelines, United States, 2013-2014. Prev Chronic Dis 2016;13:160261. DOI: https://doi.org/10.5888/pcd13.160261.

\section{PEER REVIEWED}

\section{Abstract}

\section{Introduction}

Neighborhood factors are increasingly recognized as determinants of health. Neighborhood social cohesion may be associated with physical activity, but previous studies examined data aggregated across racial/ethnic groups. We assessed whether neighborhood social cohesion was associated with physical activity in a nationally representative data set and explored the role of race/ethnicity.

\section{Methods}

We combined National Health Interview Survey data from 2013 and $2014(n=64,754)$ and constructed a neighborhood social cohesion score by summing responses to 4 questions. The outcome of meeting aerobic physical activity guidelines was defined as 150 or more minutes per week of moderate activity or 75 or more minutes of vigorous activity. Multivariable models regressing physical activity on neighborhood social cohesion were adjusted for demographic factors; interaction analyses assessed effect modification by race/ethnicity.

\section{Results}

In adjusted analyses, a 1-unit increase in the neighborhood social cohesion score was associated with higher odds of meeting physical activity guidelines (odds ratio [OR], 1.04; 95\% confidence in- terval [CI], 1.03-1.05). Neighborhood social cohesion and physical activity were associated among non-Hispanic white adults (OR, 1.30; 95\% CI, 1.20-1.42) and Hispanic adults (OR, 1.18; 95\% CI, 1.03-1.34]) but not among non-Hispanic black or Asian American adults (Chinese, Filipino, and Asian Indians).

\section{Conclusion}

Neighborhood social cohesion was associated with meeting physical activity guidelines in a nationally representative sample; this association may be most meaningful for non-Hispanic white and Hispanic populations. Additional studies are needed to identify neighborhood factors that help non-Hispanic black and Asian Americans to meet physical activity guidelines.

\section{Introduction}

Physical activity is a beneficial health behavior, associated with reduced risk of several health conditions including obesity, cancer, and other chronic diseases (1-4). According to national data published in 2014, only $36 \%$ of adults were aware of the 2008 Physical Activity Guidelines for Americans (5) and only 52\% of adults met the aerobic guidelines (6). Racial/ethnic disparities exist for physical activity: racial/ethnic minority populations are less likely to be physically active than the white population $(7,8)$, and Asian Americans have the lowest activity levels $(9,10)$.

Neighborhood factors are increasingly recognized as determinants of health and of health behaviors, including physical activity (11-16). Neighborhood social cohesion, a construct of the social environment, is the perceived degree of connectedness between and among neighbors and their willingness to intervene for the common good (11). Neighborhood social cohesion may influence physical activity behaviors through greater social support or communication, reinforcement of social norms (positive or negative) for exercise, or greater access to parks or green spaces $(11,17)$. 
Neighborhood social cohesion has been associated with meeting physical activity guidelines and regular physical activity (18). However, the findings of analyses disaggregated by racial/ethnic group are mixed. Analyses of California Health Interview Survey data showed that neighborhood social cohesion was associated with walking for physical activity among white and Hispanic adults but not among black and Asian American adults (19) and among older Chinese adults but not Filipino, Japanese, Korean, or Vietnamese adults (20).

The objectives of this analysis were to 1) characterize factors associated with higher levels of neighborhood social cohesion, 2) assess the association between neighborhood social cohesion and aerobic physical activity in a large, nationally representative data set, and 3) explore the role of race/ethnicity as a potential confounder or effect modifier in the association between neighborhood social cohesion and physical activity. We hypothesized that neighborhood social cohesion and aerobic physical activity are positively associated and that this association would be modified by race/ethnicity.

\section{Methods}

We combined data from the National Health Interview Survey (NHIS) 2013 and 2014 survey waves ( $\mathrm{n}=71,254$ adults). NHIS is an annual cross-sectional health survey conducted among the US population in English and Spanish continuously throughout the year $(21,22)$. Data are self-reported and collected by trained interviewers in the US Census Bureau; interviewers use computer-assisted personal interviewing, a data collection method in which an interviewer meets with a respondent face-to-face to ask questions and enter answers into a laptop computer.

\section{Definitions of key variables}

The NHIS in 2013 and 2014 included 4 questions on neighborhood social cohesion, modified from an original scale of 5 questions developed by the Project on Human Development in Chicago Neighborhoods Community Survey (23). Participants rated agreement or disagreement on a 4-point scale (1, definitely agree; 2 , somewhat agree; 3 , somewhat disagree; and 4 , definitely disagree) with the following 4 statements: 1) People in this neighborhood help each other out; 2) There are people I can count on in this neighborhood; 3) People in this neighborhood can be trusted; and 4) This is a close-knit neighborhood. Participant responses were then reverse coded (eg, definitely agree was assigned a value of 4 instead of 1); thus a higher score equated higher neighborhood social cohesion. A neighborhood social cohesion score was constructed by summing the responses to the questions, with a possible range of scores from 4 to 16 . Neighborhood social cohesion was treated as both a continuous variable (ie, difference associated with 1-unit change in score) and as a binary variable, categorized as at or above the median score or below the median score.

Using a series of 8 questions, the NHIS measured leisure-time physical activity. Vigorous activity was assessed by asking 2 questions, starting with, "How often do you do vigorous leisure-time physical activities for at least 10 minutes that cause heavy sweating or large increases in breathing or heart rate?" The next question asked about frequency (per day, week, month, and year). Participants also reported on how long they performed these vigorous activities. Similarly, moderate activity was assessed by starting with the following question: "How often do you do light or moderate leisure-time physical activities for at least 10 minutes that cause only light sweating or a slight to moderate increase in breathing or heart rate?" Frequency and how long they performed these moderate activities were assessed in subsequent questions. Data on physical activity were cleaned and recoded as per NHIS protocol for leisure-time physical activity (24). The primary outcome was defined as meeting guidelines on aerobic physical activity $(\geq 150$ minutes per week of moderate or $\geq 75$ minutes per week of vigorous physical activity) (25). As per protocol for defining moderate-equivalent minutes, minutes per week of vigorous physical activity were multiplied by 2 (24). The secondary outcome was total number of moderate or moderate-equivalent minutes per week of aerobic physical activity, modeled as a continuous variable.

Other covariates were age $(18-44,45-64$, or $\geq 65$ y), racial/ethnic group (non-Hispanic white, non-Hispanic black, Hispanic, nonHispanic Chinese, non-Hispanic Filipino, or non-Hispanic Asian Indian), sex, education (data restricted to those aged $\geq 25 \mathrm{y}[<$ high school diploma, high school diploma or equivalent, some college, college graduate, or graduate degree]), annual income $(<\$ 20,000$, $\$ 20,000$ to $<\$ 45,000, \$ 45,000$ to $<\$ 75,000$, or $\geq \$ 75,000$ ), nativity (born in United States or foreign born) and English language proficiency (speaks very well or not very well). Length of time living in one's neighborhood was assessed with the question, "About how long have you lived in your present neighborhood?"; response choices were less than 1 year, 1 to 3 years, 4 to 10 years, 11 to 20 years, and more than 20 years.

\section{Statistical analysis}

Of the 71,254 adults in the 2 years of the NHIS, 5,663 respondents were missing data on neighborhood social cohesion variables, and 1,276 respondents were missing data on the physical activity

\footnotetext{
The opinions expressed by authors contributing to this journal do not necessarily reflect the opinions of the U.S. Department of Health and Human Services, the Public Health Service, the Centers for Disease Control and Prevention, or the authors' affiliated institutions.
} 
variables needed to calculate whether they met physical activity guidelines; these respondents were not included in the analysis. The final analytic sample size was 64,754 (439 respondents were missing both neighborhood social cohesion and physical activity).

Data were weighted to be representative of the noninstitutionalized adult population in the United States. Demographic and other characteristics were assessed overall and then stratified by median neighborhood social cohesion score (at or above median score or below median score). Differences between those at or above the median score and those below the median score were assessed by using $\chi^{2}$ tests. We also estimated mean neighborhood social cohesion score. To characterize factors associated with higher levels of neighborhood social cohesion, all covariates (age group, race/ethnicity, sex, education, annual income, nativity, English language proficiency, and length of time in neighborhood) were included in a multivariable regression model.

We ran multivariable models regressing physical activity outcomes on neighborhood cohesion; we used logistic regression models for the binary outcome of meeting physical activity guidelines, and linear regression models for the continuous outcome of moderate or moderate-equivalent minutes per week of physical activity. Both models were run as crude models, then adjusted for race/ethnicity, and then adjusted for age, race/ethnicity, sex, education, annual income, nativity, English language proficiency, and length of time living in the neighborhood. Education and annual income were moderately correlated $(\rho=0.38, P<$ $.001)$, so we ran models that excluded one or the other. Results did not change substantially in either model; thus, our final models adjusted for both variables. To assess effect modification by race/ ethnicity, we ran a logistic regression model that included an interaction term between race/ethnicity and binary neighborhood cohesion. All analyses were conducted using complex survey weighting techniques, and data were analyzed using Stata version 12.1 (StataCorp LP) and Sudaan version 11.0.1 (RTI International).

\section{Results}

The greatest portion $(46.7 \%)$ of the overall sample was aged 18 to 44; $67 \%$ were non-Hispanic white, $51.7 \%$ were women, and $44.3 \%$ had a college or graduate degree (Table 1). The median neighborhood social cohesion score was 12.0. Neighborhood social cohesion scores at or above the median were associated with all demographic characteristics examined: older age, non-Hispanic white race/ethnicity, female sex, having a college degree and higher income, being born in the United States, English language proficiency, and having lived in the neighborhood longer. Neighborhood social cohesion scores at or above the median were also associated with a slightly higher prevalence of meeting aerobic physical activity guidelines (51.5\% for scores $\geq$ median vs $45.6 \%$ for scores $<$ median; $P=.001$ ) and with a greater number of moderate or moderate-equivalent minutes per week of physical activity $(371.0 \mathrm{~min} /$ week for scores $\geq$ median vs $319.3 \mathrm{~min} /$ week for scores $<$ median, $P=.001)$. The overall mean neighborhood social cohesion score was 12.4. After adjustment for each other, the following covariates remained associated with neighborhood social cohesion: being aged 65 or older $(0.41$ score units higher than the score for those aged 18-44; $P<.001$ ); being non-Hispanic black (1.00 score units lower than the score for non-Hispanic whites; $P<$ $.001)$ or Hispanic $(0.72$ score units lower than the score for nonHispanic whites; $P<.001)$; having higher education levels $(0.37$ score units higher for some college, 0.48 score units higher for college graduate, and 0.70 score units higher for graduate degree, all compared with less than a high school diploma, $P<.001$ for all); having higher income levels ( 0.38 score units higher for those with incomes of $\$ 45,000$ to $<\$ 75,000$ and 0.71 score units higher for those with incomes of $\geq \$ 75,000$, compared with incomes of $<\$ 20,000 ; P<.001$ for both); and having lived longer in the neighborhood $(0.70$ score units higher for those in the neighborhood for 4-10 y, 1.08 score units higher for those in the neighborhood for $11-20 \mathrm{y}$, and 1.30 score units higher for those in the neighborhood for $>20 \mathrm{y}$, compared with those in the neighborhood for $<1$ y; $P<.001$ for all). The correlation between neighborhood social cohesion and length of time living in the neighborhood was weak but significant $(\rho=0.17, P<.001)$.

After adjustment for all covariates, the odds of meeting aerobic physical activity guidelines associated with a 1-unit increase in the neighborhood social cohesion score were 1.04 (95\% confidence interval $[\mathrm{CI}], 1.03-1.05 ; P<.001)$, whereas the odds of meeting aerobic physical activity guidelines were 1.22 (95\% CI, 1.13-1.32; $P<.001)$ for a neighborhood social cohesion score at or above the median compared with a score below the median (Table 2). Results did not change substantially from the crude model when we adjusted for race/ethnicity. A 1-unit increase in the neighborhood social cohesion score was associated with 6.9 minutes $(95 \% \mathrm{CI}$, 3.5-10.4 min; $P<.001$ ) more of moderate or moderate-equivalent minutes per week of physical activity after adjustment. Similarly, a neighborhood social cohesion score at or above the median was associated with 45.3 minutes (95\% CI, 22.1-68.6 min; $P<.001$ ) more of moderate or moderate-equivalent physical activity minutes per week compared with a social cohesion score below the median. In interaction analyses, the overall interaction term was significant $(P=.003)$. After adjustment, consistent associations between neighborhood social cohesion and aerobic physical activity remained among non-Hispanic whites only; those who had neighborhood social cohesion scores at or above the median had a higher odds of meeting aerobic physical activity guidelines $(\mathrm{OR}=1.30 ; 95 \% \mathrm{CI}, 1.20-1.42 ; P<.001$; Table 3$)$ and had more

The opinions expressed by authors contributing to this journal do not necessarily reflect the opinions of the U.S. Department of Health and Human Services, the Public Health Service, the Centers for Disease Control and Prevention, or the authors' affiliated institutions. 
moderate or moderate-equivalent minutes per week of physical activity (58.1 minutes; 95\% CI, 30.4-85.8 min; $P<.001$ ) than those with scores below the median. For Hispanic respondents, we found greater odds of meeting aerobic physical activity guidelines among those reporting neighborhood social cohesion scores at or above the median than among those reporting neighborhood social cohesion scores below the median $(\mathrm{OR}=1.18$; 95\% CI, $1.03-1.34, P=.01)$.

\section{Discussion}

In a nationally representative sample of noninstitutionalized adults in the United States, higher levels of neighborhood social cohesion were associated with higher odds of meeting aerobic physical activity guidelines and more moderate or moderate-equivalent minutes of physical activity per week. The effect estimate observed in our study for the odds of meeting aerobic physical activity guidelines ( $\mathrm{OR}=1.04 ; 95 \% \mathrm{CI}, 1.03-1.05)$ was similar in magnitude to a previous study that examined the same association in a multiethnic sample of US adults (OR $=1.03 ; 95 \% \mathrm{CI}, 1.01-1.05)$ (18). Our study expands on this previous study by using interaction analyses to assess data for various racial/ethnic groups. In our study, the association may have been driven primarily by non-Hispanic white adults and to a lesser degree, Hispanic adults. A similar result was observed in an analysis of data representative of the adult population in California: higher levels of neighborhood social cohesion were associated overall with more walking (OR, $1.09 ; 95 \% \mathrm{CI}, 1.04-1.14)$, but by racial/ethnic group, only among non-Hispanic white and Hispanic adults (19).

Neighborhood social cohesion in our study was moderately high, with a mean value of 12.4 of a maximum value of 16 . The factors associated with higher levels of neighborhood social cohesion included older age, being non-Hispanic white or a college graduate, having a higher annual income, and living in the neighborhood for more than 20 years. These results are unsurprising but offer insight into the adult populations in the United States who are likely to perceive and report higher levels of neighborhood social cohesion. Similarly, one can imagine that people reporting higher levels of neighborhood social cohesion may also be those who have higher levels of health literacy, better access to safe facilities for exercise, and more time and means to access those facilities. Future analyses examining the potential mediating effects of these factors on the association between neighborhood social cohesion and activity behaviors are warranted.

Although we did not find any associations between neighborhood social cohesion and physical activity among non-Hispanic Chinese adults, non-Hispanic Filipino adults, or non-Hispanic Asian Indian adults, other studies using regional samples and in-language re- cruitment found different results. For example, an analysis using data on adults aged 55 or older from the California Health Interview Survey found that higher levels of neighborhood social cohesion were associated with lower odds of not walking for leisure or transport among Chinese Americans (OR $=0.39 ; 95 \% \mathrm{CI}$, $0.17-0.89$ ) but not among Filipino, Korean, or Vietnamese Americans (20). In an analysis using data from a cross-sectional health assessment of foreign-born Chinese American immigrants in New York City $(n=1,772)$, higher levels of neighborhood social cohesion were associated with higher odds of meeting physical activity guidelines and with less sitting time (unpublished data, S.S.Y. et al, July 2016). Because the NHIS is conducted only in English and Spanish, it may recruit a nonrepresentative sample of immigrants $(26,27)$ (ie, who are highly acculturated or US born, have high incomes, or do not live in urban areas), and the differences in samples may explain discrepancies in observations across these studies. The analysis of Chinese American immigrants in New York City in particular offers evidence that health literacy may be less of a factor in the association between neighborhood social cohesion and activity behaviors, because the cohort recruited had fairly low socioeconomic and acculturation status. Instead, perhaps ready access to safe places to exercise (eg, green space and gyms in suburban areas, high walkability in urban areas) may be more of a mediating factor.

The strengths of this study are large sample sizes, even for subgroups, and that results are applicable broadly to the adult population in the United States. Although physical activity was not directly measured, the use of a series of questions and self-reported data are considered valid and acceptable methods for surveying the physical activity behaviors of large samples of people (28). The limitations of this analysis are that data were collected by selfreport, making responses prone to social desirability bias. The dichotomous variable of meeting aerobic physical activity guidelines may be more meaningful than the continuous values of physical activity. The ideal approach would be to use detailed biometric data obtained through direct observation, time diaries, and metabolic measures; however, at the population level, this approach is cost prohibitive (29). Thus, for assessing physical activity in large populations, self-reported responses on questionnaires, although not perfect, is a feasible method (28). The results of this study are generalizable only to the English-speaking and Spanish-speaking adult populations in the United States. Lastly, because this study was cross-sectional, the directionality of cause and effect of the association between neighborhood social cohesion and physical activity cannot be established.

Although social factors such as neighborhood social cohesion have become salient in public health, the applicability of these factors in the context of race/ethnicity or cultural nuance needs to

\footnotetext{
The opinions expressed by authors contributing to this journal do not necessarily reflect the opinions of the U.S. Department of Health and Human Services, the Public Health Service, the Centers for Disease Control and Prevention, or the authors' affiliated institutions.
} 
be carefully examined. Future analyses should focus on racial/ethnic groups and subgroups (eg, Mexican vs Puerto Rican, Chinese vs Vietnamese) to fully characterize the effects of these broad social determinants of health. In addition, studies are needed to determine factors that predict physical activity behaviors for nonHispanic black and Asian American populations, acknowledging that "one size does not fit all" in the prevention of chronic disease.

\section{Acknowledgments}

This research was supported in part by grant no. P60MD000538 from the National Institutes of Health (NIH) National Institute on Minority Health and Health Disparities, grant nos. U48DP005008 and U58DP005621 from the Centers for Disease Control and Prevention (CDC), and grant no. UL1TR001445 from the National Center for Advancing Translational Sciences/NIH. The contents of this publication are solely the responsibility of the authors and do not necessarily represent the official views of the NIH or CDC.

\section{Author Information}

Corresponding Author: Stella S. Yi, PhD, MPH, New York University School of Medicine, Department of Population Health, 550 First Ave, VZN Suite 844, 8th Floor, New York, NY 10016. Telephone: 212-263-5163. Email: stella.yi@nyumc.org.

Author Affiliations: ${ }^{1}$ New York University School of Medicine, New York, New York. ${ }^{2}$ University of California, San Francisco, San Francisco, California.

\section{References}

1. Artinian NT, Fletcher GF, Mozaffarian D, Kris-Etherton P, Van Horn L, Lichtenstein AH, et al. Interventions to promote physical activity and dietary lifestyle changes for cardiovascular risk factor reduction in adults: a scientific statement from the American Heart Association. Circulation 2010;122(4):406-41.

2. Dunton GF, Berrigan D, Ballard-Barbash R, Graubard B, Atienza AA. Joint associations of physical activity and sedentary behaviors with body mass index: results from a time use survey of US adults. Int J Obes 2009;33(12):1427-36.

3. Friedenreich CM, Orenstein MR. Physical activity and cancer prevention: etiologic evidence and biological mechanisms. J Nutr 2002;132(11,Suppl):3456S-64S.

4. Must A, Tybor DJ. Physical activity and sedentary behavior: a review of longitudinal studies of weight and adiposity in youth. Int J Obes 2005;29(Suppl 2):S84-96.
5. Kay MC, Carroll DD, Carlson SA, Fulton JE. Awareness and knowledge of the 2008 Physical Activity Guidelines for Americans. J Phys Act Health 2014;11(4):693-8.

6. Centers for Disease Control and Prevention. Adult participation in aerobic and muscle-strengthening physical activities — United States, 2011. MMWR Morb Mortal Wkly Rep 2013;62(17):326-30.

7. August KJ, Sorkin DH. Racial/ethnic disparities in exercise and dietary behaviors of middle-aged and older adults. J Gen Intern Med 2011;26(3):245-50.

8. Bolen JC, Rhodes L, Powell-Griner EE, Bland SD, Holtzman D. State-specific prevalence of selected health behaviors, by race and ethnicity - Behavioral Risk Factor Surveillance System, 1997. MMWR CDC Surveill Summ 2000;49(2):1-60.

9. Kandula NR, Lauderdale DS. Leisure time, non-leisure time, and occupational physical activity in Asian Americans. Ann Epidemiol 2005;15(4):257-65.

10. Yi SS, Roberts C, Lightstone AS, Shih M, Trinh-Shevrin C. Disparities in meeting physical activity guidelines for AsianAmericans in two metropolitan areas in the United States. Ann Epidemiol 2015;25(9):656-660.e2, e2.

11. McNeill LH, Kreuter MW, Subramanian SV. Social environment and physical activity: a review of concepts and evidence. Soc Sci Med 2006;63(4):1011-22.

12. Shi L, Zhang D, van Meijgaard J, MacLeod KE, Fielding JE. The interaction between an individual's acculturation and community factors on physical inactivity and obesity: a multilevel analysis. Am J Public Health 2015;105(7):1460-7.

13. Booth KM, Pinkston MM, Poston WS. Obesity and the built environment. J Am Diet Assoc 2005;105(5,Suppl 1):S110-7.

14. Christine PJ, Auchincloss AH, Bertoni AG, Carnethon MR, Sánchez BN, Moore K, et al. Longitudinal associations between neighborhood physical and social environments and incident type 2 diabetes mellitus: the Multi-Ethnic Study of Atherosclerosis (MESA). JAMA Intern Med 2015; 175(8):1311-20.

15. Sallis JF, Floyd MF, Rodríguez DA, Saelens BE. Role of built environments in physical activity, obesity, and cardiovascular disease. Circulation 2012;125(5):729-37.

16. Diez Roux AV. Investigating neighborhood and area effects on health. Am J Public Health 2001;91(11):1783-9.

17. Cohen DA, Inagami S, Finch B. The built environment and collective efficacy. Health Place 2008;14(2):198-208.

18. Samuel LJ, Dennison Himmelfarb CR, Szklo M, Seeman TE, Echeverria SE, Diez Roux AV. Social engagement and chronic disease risk behaviors: the Multi-Ethnic Study of Atherosclerosis. Prev Med 2015;71:61-6.

19. Wen M, Kandula NR, Lauderdale DS. Walking for transportation or leisure: what difference does the neighborhood make? J Gen Intern Med 2007;22(12):1674-80.

The opinions expressed by authors contributing to this journal do not necessarily reflect the opinions of the U.S. Department of Health and Human Services, the Public Health Service, the Centers for Disease Control and Prevention, or the authors' affiliated institutions. 
20. Li Y, Kao D, Dinh TQ. Correlates of neighborhood environment with walking among older Asian Americans. J Aging Health 2015;27(1):17-34.

21. National Center for Health Statistics. National Health Interview Survey, 2013. Public-use data file and documentation. http://www.cdc.gov/nchs/nhis/quest_data related_1997_forward.htm. Accessed February 1, 2016.

22. National Center for Health Statistics. 2013 National Health Interview Survey (NHIS) public use data release survey description. 2014. ftp://ftp.cdc.gov/pub/Health_Statistics/ NCHS/ Dataset_Documentation/NHIS/2013/ srvydesc.pdf. Accessed February 1, 2016.

23. Sampson RJ, Raudenbush SW, Earls F. Neighborhoods and violent crime: a multilevel study of collective efficacy. Science 1997;277(5328):918-24.

24. National Health Interview Survey. Adult physical activity information. Leisure-time physical activity recodes. http:// www.cdc.gov/nchs/nhis/physical_activity/pa_recodes.htm. Accessed February 1, 2016.

25. US Department of Health and Human Services. 2008 Physical activity guidelines for Americans. http://www.health.gov/ paguidelines/pdf/paguide.pdf. Accessed October 25, 2016.

26. Holland AT, Palaniappan LP. Problems with the collection and interpretation of Asian-American health data: omission, aggregation, and extrapolation. Ann Epidemiol 2012; 22(6):397-405.

27. Islam NS, Khan S, Kwon S, Jang D, Ro M, Trinh-Shevrin C. Methodological issues in the collection, analysis, and reporting of granular data in Asian American populations: historical challenges and potential solutions. J Health Care Poor Underserved 2010;21(4):1354-81.

28. Shephard RJ. Limits to the measurement of habitual physical activity by questionnaires. Br J Sports Med 2003; 37(3):197-206, discussion 206.

29. Matthews CE, Moore SC, George SM, Sampson J, Bowles HR. Improving self-reports of active and sedentary behaviors in large epidemiologic studies. Exerc Sport Sci Rev 2012; 40(3):118-26.

\footnotetext{
The opinions expressed by authors contributing to this journal do not necessarily reflect the opinions of the U.S. Department of Health and Human Services, the Public Health Service, the Centers for Disease Control and Prevention, or the authors' affiliated institutions.
} 


\section{Tables}

Table 1. Demographic Characteristics of US Adults, Overall and by Neighborhood Social Cohesion ${ }^{a}$, National Health Interview Survey, 2013-2014

\begin{tabular}{|c|c|c|c|c|c|c|c|}
\hline \multirow[b]{3}{*}{ Characteristic } & \multirow{2}{*}{\multicolumn{2}{|c|}{ Overall }} & \multicolumn{4}{|c|}{ Neighborhood Social Cohesion Score ${ }^{c}$} & \multirow[b]{3}{*}{$P$ Value $^{\mathrm{d}}$} \\
\hline & & & \multicolumn{2}{|c|}{ At or Above Median } & \multicolumn{2}{|c|}{ Below Median } & \\
\hline & Unweighted No. & Weighted $\%^{b}$ & Unweighted No. & Weighted $\%^{b}$ & Unweighted No. & Weighted $\%^{b}$ & \\
\hline Overall & 64,754 & 100 & 42,972 & - & 21,782 & - & - \\
\hline \multicolumn{8}{|l|}{ Age group, $y$} \\
\hline $18-44$ & 27,980 & 46.7 & 16,705 & 43.0 & 11,275 & 54.4 & \multirow{3}{*}{.001} \\
\hline $45-64$ & 21,830 & 34.8 & 14,867 & 35.9 & 6,963 & 32.5 & \\
\hline$\geq 65$ & 14,944 & 18.5 & 3,544 & 21.1 & 3,544 & 13.0 & \\
\hline \multicolumn{8}{|l|}{ Race/ethnicity } \\
\hline Non-Hispanic white & 40,225 & 67.0 & 28,788 & 71.4 & 11,437 & 57.7 & \multirow{6}{*}{.001} \\
\hline Non-Hispanic black & 9,088 & 11.6 & 5,255 & 9.9 & 3,833 & 15.0 & \\
\hline Hispanic & 10,808 & 15.0 & 5,912 & 12.3 & 4,896 & 20.7 & \\
\hline Non-Hispanic Chinese & 778 & 1.1 & 496 & 1.1 & 282 & 1.1 & \\
\hline Non-Hispanic Filipino & 841 & 1.2 & 587 & 1.2 & 254 & 1.0 & \\
\hline Non-Hispanic Asian Indian & 717 & 1.2 & 536 & 1.4 & 181 & 0.8 & \\
\hline \multicolumn{8}{|l|}{ Sex } \\
\hline Male & 28,957 & 48.3 & 19,499 & 48.8 & 9,458 & 47.3 & \multirow{2}{*}{.004} \\
\hline Female & 35,797 & 51.7 & 23,473 & 51.2 & 12,324 & 52.7 & \\
\hline \multicolumn{8}{|l|}{ Education $^{\mathrm{e}}$} \\
\hline$<$ High school diploma & 9,029 & 13.2 & 5,442 & 11.6 & 3,587 & 16.9 & \multirow{5}{*}{.001} \\
\hline Grade 12 or GED & 15,006 & 25.3 & 9,899 & 24.3 & 5,107 & 27.3 & \\
\hline Some college & 10,262 & 17.3 & 6,817 & 17.1 & 3,445 & 17.6 & \\
\hline College graduate & 17,667 & 32.2 & 12,471 & 33.5 & 5,196 & 29.2 & \\
\hline Graduate degree & 6,556 & 12.1 & 4,930 & 13.4 & 1,626 & 9.0 & \\
\hline \multicolumn{8}{|l|}{ Annual income, \$ } \\
\hline$<20,000$ & 10,581 & 29.0 & 6,319 & 26.4 & 4,262 & 34.3 & \multirow{4}{*}{.001} \\
\hline 20,000 to $<45,000$ & 12,316 & 33.5 & 7,743 & 32.0 & 4,573 & 36.4 & \\
\hline 45,000 to $<75,000$ & 7,156 & 21.2 & 5,022 & 22.5 & 2,134 & 18.5 & \\
\hline$\geq 75,000$ & 4,918 & 16.4 & 3,788 & 19.0 & 1,130 & 10.8 & \\
\hline
\end{tabular}

Abbreviations: GED, general educational development.

a The perceived degree of connectedness between and among neighbors and their willingness to intervene for the common good (11).

${ }^{\mathrm{b}}$ All estimates are weighted to be representative of the US adult noninstitutionalized population.

${ }^{\mathrm{C}}$ Constructed by summing the responses to 4 questions: 1) People in this neighborhood help each other out; 2) There are people I can count on in this neighborhood; 3) People in this neighborhood can be trusted; and 4) This is a close-knit neighborhood. Scores could range from 4 to 16 , with higher scores indicating greater agreement with statements. The median score was 12.0.

${ }^{\mathrm{d}}$ Determined by using $t$ tests for continuous variables and $t$ tests for proportions for categorical variables.

${ }^{\mathrm{e}}$ Data on education were restricted to respondents aged $\geq 25 \mathrm{y}$.

${ }^{\mathrm{f}}$ Defined as 150 or more minutes per week of moderate activity or 75 or more minutes of vigorous activity (25). 
(continued)

Table 1. Demographic Characteristics of US Adults, Overall and by Neighborhood Social Cohesion ${ }^{a}$, National Health Interview Survey, 2013-2014 ${ }^{b}$

\begin{tabular}{|c|c|c|c|c|c|c|c|}
\hline \multirow[b]{3}{*}{ Characteristic } & & & \multicolumn{4}{|c|}{ Neighborhood Social Cohesion Score ${ }^{c}$} & \multirow[b]{3}{*}{$P$ Value $^{\mathrm{d}}$} \\
\hline & \multicolumn{2}{|c|}{ Overall } & \multicolumn{2}{|c|}{ At or Above Median } & \multicolumn{2}{|c|}{ Below Median } & \\
\hline & Unweighted No. & Weighted $\%^{\mathrm{b}}$ & Unweighted No. & Weighted $\%^{\mathrm{b}}$ & Unweighted No. & Weighted $\%^{\mathrm{b}}$ & \\
\hline \multicolumn{8}{|l|}{ Nativity } \\
\hline Born in United States & 52,885 & 82.1 & 35,940 & 83.9 & 16,945 & 78.4 & \multirow{2}{*}{.001} \\
\hline Foreign born & 11,852 & 17.9 & 7,021 & 16.1 & 4,831 & 21.6 & \\
\hline \multicolumn{8}{|l|}{ How well English is spoken } \\
\hline Very well & 43,463 & 88.7 & 29,533 & 90.4 & 13,930 & 85.0 & \multirow{2}{*}{.001} \\
\hline Not very well & 6,273 & 11.3 & 3,593 & 9.6 & 2,680 & 15.0 & \\
\hline \multicolumn{8}{|l|}{ Length of time living in neighborhood, $y$} \\
\hline$<1$ & 8,227 & 11.7 & 4,685 & 10.1 & 3,542 & 15.2 & \multirow{5}{*}{.001} \\
\hline $1-3$ & 13,567 & 19.9 & 7,933 & 17.6 & 5,634 & 25.0 & \\
\hline $4-10$ & 17,015 & 27.0 & 11,259 & 23.9 & 5,756 & 27.1 & \\
\hline $11-20$ & 11,517 & 19.5 & 8,175 & 20.9 & 3,342 & 16.7 & \\
\hline$>20$ & 14,369 & 21.8 & 10,886 & 24.5 & 3,483 & 16.0 & \\
\hline Meeting aerobic physical activity guidelines ${ }^{f}$ & 31,107 & 49.6 & 21,345 & 51.5 & 9,762 & 45.6 & .001 \\
\hline $\begin{array}{l}\text { Moderate or moderate-equivalent minutes } \\
\text { per week of physical activity, mean }\end{array}$ & 64,290 & 354.3 & 42,646 & 371.0 & 21,644 & 319.3 & .001 \\
\hline
\end{tabular}

Abbreviations: GED, general educational development.

${ }^{\mathrm{a}}$ The perceived degree of connectedness between and among neighbors and their willingness to intervene for the common good (11).

${ }^{\mathrm{b}}$ All estimates are weighted to be representative of the US adult noninstitutionalized population.

${ }^{c}$ Constructed by summing the responses to 4 questions: 1) People in this neighborhood help each other out; 2) There are people I can count on in this neighborhood; 3) People in this neighborhood can be trusted; and 4) This is a close-knit neighborhood. Scores could range from 4 to 16 , with higher scores indicating greater agreement with statements. The median score was 12.0.

${ }^{d}$ Determined by using $t$ tests for continuous variables and $t$ tests for proportions for categorical variables.

${ }^{e}$ Data on education were restricted to respondents aged $\geq 25 \mathrm{y}$.

${ }^{f}$ Defined as 150 or more minutes per week of moderate activity or 75 or more minutes of vigorous activity (25).

The opinions expressed by authors contributing to this journal do not necessarily reflect the opinions of the U.S. Department of Health and Human Services, the Public Health Service, the Centers for Disease Control and Prevention, or the authors' affiliated institutions. 
Table 2. Multivariable Regression Models, Neighborhood Social Cohesion ${ }^{a}$ Score ${ }^{b}$ and Physical Activity Outcomes, National Health Interview Survey, $2013-2014$

\begin{tabular}{|c|c|c|c|}
\hline Variable & Crude & Adjusted for Race/Ethnicity & Adjusted for All Covariates ${ }^{c}$ \\
\hline \multicolumn{4}{|c|}{ Meeting aerobic physical activity guidelines ${ }^{d}$, OR $(95 \% \mathrm{Cl})\left[P\right.$ value $\left.^{\mathrm{e}}\right]$} \\
\hline $\begin{array}{l}\text { Neighborhood social cohesion score, per 1-unit } \\
\text { change }\end{array}$ & $1.04(1.03-1.05)[<.001]$ & $1.04(1.03-1.05)[<.001]$ & $1.04(1.03-1.05)[<.001]$ \\
\hline $\begin{array}{l}\text { Neighborhood social cohesion score at or above } \\
\text { vs below median }\end{array}$ & $1.22(1.20-1.33)[<.001]$ & $1.22(1.16-1.28)[<.001]$ & $1.22(1.13-1.32)[<.001]$ \\
\hline \multicolumn{4}{|c|}{ Moderate-equivalent minutes per week of physical activity, $\beta$ coefficient $(95 \% \mathrm{Cl})\left[P\right.$ value $\left.{ }^{e}\right]$} \\
\hline $\begin{array}{l}\text { Neighborhood social cohesion score, per 1-unit } \\
\text { change }\end{array}$ & $7.8(5.5-10.1)[<.001]$ & $7.0(4.7-9.4)[<.001]$ & $6.9(3.5-10.4)[<.001]$ \\
\hline $\begin{array}{l}\text { Neighborhood social cohesion score at or above } \\
\text { vs below median }\end{array}$ & $51.7(36.5-66.8)[<.001]$ & $47.6(32.5-62.7)[<.001]$ & $45.3(22.1-68.6)[<.001]$ \\
\hline
\end{tabular}

Abbreviations: $\mathrm{Cl}$, confidence interval; OR, odds ratio.

${ }^{a}$ The perceived degree of connectedness between and among neighbors and their willingness to intervene for the common good (11).

${ }^{\mathrm{b}}$ Constructed by summing the responses to 4 questions: 1) People in this neighborhood help each other out; 2) There are people I can count on in this neighborhood; 3) People in this neighborhood can be trusted; and 4) This is a close-knit neighborhood. Scores could range from 4 to 16 , with higher scores indicating greater agreement with statements. The median score was 12.0.

${ }^{\mathrm{C}}$ All covariates are age, sex, race/ethnicity, education, annual income, nativity (US born or not), English language proficiency, and length of time in neighborhood.

${ }^{d}$ Defined as 150 or more minutes per week of moderate activity or 75 or more minutes of vigorous activity (25).

${ }^{\mathrm{e}}$ Determined by using multivariable logistic (categorical outcome) or linear (continuous outcome) regression. 
Table 3. Effect Modification of Neighborhood Social Cohesion ${ }^{\text {a }}$ on Physical Activity Outcomes, by Race/Ethnicity, National Health Interview Survey, 2013-2014

\begin{tabular}{|c|c|c|c|c|}
\hline Neighborhood Social Cohesion Score ${ }^{b}$ & $\begin{array}{l}\text { Meeting Aerobic Physical Activity } \\
\text { Guidelines' }{ }^{c}, \text { OR (95\% Cl) }\end{array}$ & $P$ Value $^{\mathrm{d}}$ & $\begin{array}{l}\text { Moderate-Equivalent Physical Activitye, } \\
\text { Min/Week, } \beta \text { Coefficient }(95 \% \mathrm{Cl})\end{array}$ & $P$ Value $^{\mathrm{d}}$ \\
\hline \multicolumn{5}{|l|}{ Overall } \\
\hline Below median & 1 [Reference] & \multirow{2}{*}{$<.001$} & 1 [Reference] & \multirow{2}{*}{$<.001$} \\
\hline At or above median & $1.22(1.13$ to 1.32$)$ & & 45.3 (22.1 to 68.6$)$ & \\
\hline \multicolumn{5}{|l|}{ By race/ethnicity ${ }^{f}$} \\
\hline Non-Hispanic white & 1.30 (1.20 to 1.42$)$ & $<.001$ & 58.1 (30.4 to 85.8$)$ & $<.001$ \\
\hline Non-Hispanic black & 0.97 (0.84 to 1.10$)$ & .54 & $34.0(-17.7$ to 85.7$)$ & .24 \\
\hline Hispanic & $1.18(1.03$ to 1.34$)$ & .01 & $5.5(-32.3$ to 43.3$)$ & .62 \\
\hline Non-Hispanic Chinese & $0.80(0.56$ to 1.13$)$ & .23 & $-35.4(-101.4$ to 30.6$)$ & .45 \\
\hline Non-Hispanic Filipino & $0.88(0.63$ to 1.24$)$ & .52 & $0.1(-65.5$ to 65.7$)$ & .80 \\
\hline Non-Hispanic Asian Indian & 1.17 (0.83 to 1.66$)$ & .27 & $-12.0(-88.6$ to 64.6$)$ & .99 \\
\hline
\end{tabular}

Abbreviations: Abbreviations: $\mathrm{Cl}$, confidence interval; OR, odds ratio.

${ }^{a}$ The perceived degree of connectedness between and among neighbors and their willingness to intervene for the common good (11).

${ }^{\mathrm{b}}$ Constructed by summing the responses to 4 questions: 1) People in this neighborhood help each other out; 2) There are people I can count on in this neighborhood; 3) People in this neighborhood can be trusted; and 4) This is a close-knit neighborhood. Scores could range from 4 to 16 , with higher scores indicating greater agreement with statements. The median score was 12.0.

${ }^{C}$ Defined as 150 or more minutes per week of moderate activity or 75 or more minutes of vigorous activity (25).

${ }^{d} P$ values determined using multivariable logistic (categorical outcome) and linear (continuous outcome) regression.

${ }^{\mathrm{e}}$ For defining moderate-equivalent minutes, minutes per week of vigorous physical activity were multiplied by 2 (24).

${ }^{f}$ In this analysis, the reference group for each OR and $\beta$ coefficient is the group reporting a neighborhood social cohesion score below the median. For example, non-Hispanic whites reporting a neighborhood social cohesion score at or above the median were 1.30 times as likely to report meeting aerobic physical activity guidelines than non-Hispanic whites reporting a neighborhood social cohesion score below the median.

The opinions expressed by authors contributing to this journal do not necessarily reflect the opinions of the U.S. Department of Health and Human Services, the Public Health Service, the Centers for Disease Control and Prevention, or the authors' affiliated institutions. 